\title{
MYELOGRAPHY IN THE LUMBAR REGION WITH WATER-SOLUBLE CONTRAST MEDIUM
}

\author{
Th. Boesman, AnNakliniek, Leiden, Holland
}

Arnell and Lidström (1931) described myelography of the lumbar region with watersoluble contrast medium, but difficulties in finding the correct medium delayed the success of the method. Arnell reviewed the subject again in 1944. Werf and Prick (1949) improved the technique. In the Annakliniek at Leiden about ninety myelographies have been done with " Leo U,"* a 20 per cent solution of sodium monoiodomethanesulphonate. Seventy-three cases have been observed long enough to give an impression of the value of the method.

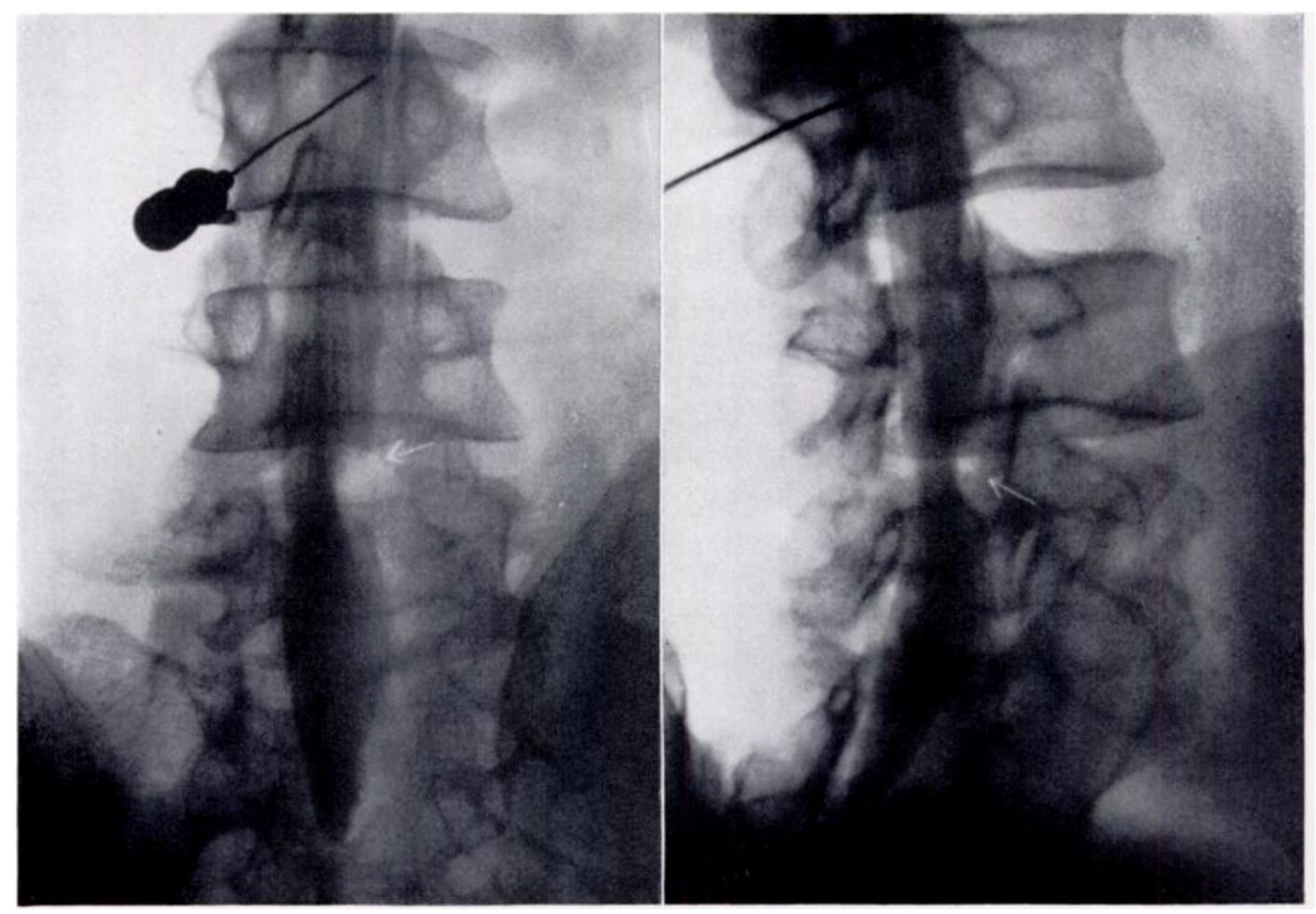

FIG. 1

Positive myelographs in a case of herniated nucleus pulposus at the L.4-5 level.

Technique-The patient lies on the side on which the lesion is suspected, with his back turned to the screen, the arms along his head. The table is tilted 20 degrees, the head on the higher side. The spinal canal is entered with a fine needle at the level of the L.3-4 interspace.

The pressure is measured and the reaction to the Queckenstedt test determined. About 10 cubic centimetres of cerebro-spinal fluid is collected for examination. One and a half cubic centimetres of 10 per cent aethocaine is now injected (Ephedrine is kept ready for injection in case of collapse) and after fifteen minutes 15 cubic centimetres of "Leo $U$ " are injected slowly, leaving the needle in place. Four radiographs are taken, with the tube directed horizontally. The projections are: 1) lying on the side on which the lesion is suspected;

* H. Lundbeck and Co. 
2) rotated 30 degrees forward; 3) rotated 45 degrees backward; 4) fully prone. When the films have been taken about 10 cubic centimetres of fluid are allowed to escape, and the needle is removed. The patient should rest for two hours half sitting in bed and then for twenty-four hours flat in bed. There has been no instance of serious ill-effect.

Results-Out of the seventy-three cases studied operation was later performed in thirty-three. In these thirty-three cases the myelography was positive twenty-six times and the operative findings were also positive (herniated discs in twenty-four cases, thickened ligamentum flavum in two cases). In three cases the myelography was doubtful but the operation findings were positive. In one case the myelography was negative and the operation findings were negative. In three cases the myelography was negative but the operative findings were positive. This represents an error of 9 per cent. Of the forty cases in which operation was not performed there was a complete conformity between the clinical findings and the myelography in twenty-two, and contradictory findings in three. This represents an error of 7.5 per cent.

In the fifteen cases in which there was no full accordance, the myelography saved the patient in eleven cases from an unnecessary operation because, on the evidence of the myelography, conservative treatment was successfully established. (A success means that a man has been fully at work again for a year or that a woman has no complaints in doing her normal work at home.) Examples of the myelographs obtained are shown in Figure 1.

The combination of accurate clinical investigation, neurological consultation, in most cases a trial of conservative treatment, and myelography proved so reliable that in this series of thirty-three operations for suspected herniated nucleus pulposus there was only one negative finding and twice a thickened ligamentum flavum. When a genuine herniation has been found the result of the operation has been very satisfactory.

\section{CONCLUSIONS}

The follow-up of these seventy-three cases suggested the following conclusions:

1. The clinical signs alone are not always sufficient to make the diagnosis of herniated nucleus pulposus with sufficient accuracy.

2. When positive, myelography was reliable as a means of localising the hernia.

3. In doubtful cases in which conservative treatment failed a clearly positive myelography turned the scale for a well-indicated operation.

4. In doubtful cases a clearly negative myelography has often rightly been a contra-indication for laminectomy.

5. No serious complication from the use of water-soluble contrast medium for myelography has been encountered.

\section{REFERENCES}

Arnell, S., and LidSTröm, F. (1931): Myelography with Skiodan (Abrodil). Acta Radiologica, 12, 287. ArNell, S. (1944): Weitere Erfahrungen über Myelographie mit Abrodil. Acta Radiologica, 25, 408. Werf, J. T. vander, and Prick, J. J. (1949): Myelographie met snel resorbeerbare contrastmiddelen ter vaststelling ener hernia nuclei pulposi. Nederlandsch Tijdschrift voor Geneeskunde, 93, 853. 